\title{
P1.49 Evaluation of the Impact of the NWC REU Program Compared with Other Undergraduate Research Experiences
}

\author{
Wilson J. Gonzalez-Espada, Ph.D. \\ Department of Physical Science \\ Arkansas Tech University \\ Daphne S. Zaras* \\ Cooperative Institute for Mesoscale Meteorological Studies \\ University of Oklahoma
}

\section{Introduction}

A growing body of research is establishing the benefit of undergraduate research experiences, namely, that students develop significant knowledge, skills, and dispositions. The National Science Foundation's Research Experiences for Undergraduates (REU) program is one of a handful of funding sources that enable atmospheric science researchers to provide such programs to undergraduate students. The National Weather Center REU program is one of these programs. The purpose of this paper is to build on previous reports by providing a research-based synthesis on the effectiveness of undergraduate research programs, summarizing the history of the NWC REU program and its positive impact on students, describing the current program and some of its unique characteristics, and using student's written comments to evaluate the program's effectiveness in terms of graduate school plans, career plan, and the student's perceived potential for scientific research. A positive, statistically significant difference was found on the graduate school question, suggesting that after the program participants reported being more even committed to attend. No statistically significant difference was found on the students' career plans and self-efficacy on becoming research scientists before and after the program. The qualitative analysis provides a context from which the statistical data can be interpreted.
*Corresponding author address: Daphne Zaras, CIMMS, University of Oklahoma, 100 E. Boyd, Suite 1110, Norman, Oklahoma 73019, Phone: (405) 325-1315, E-mail: dzaras@ou.edu

\section{Research on the Benefits of REU- Like Programs \\ Undergraduate research is increasingly} valued as a critical component of a good undergraduate science education (Halstead, 1997). Through research, it is expected that students will develop a number of behaviors and knowledge, among them an ability to do science, theoretical and practical subject matter knowledge, research and communication skills, independent thought, creativity, and a positive disposition toward the discipline (Kardash, 2000).

The involvement of undergraduate students in research is summarized in one of three metaphors: (a) the student as passive learner, where the student is taking courses in subject matter and research methods, (b) the student as a low-skill worker, where the student works as a laboratory technician and is not considered to have the skills needed for significant contributions, and (c) the student as colleague, where the student takes a significant role in many phases of the research process and initiative is rewarded (Kremer and Bringle, 1990). Research suggests that the colleague model of undergraduate research, an essential feature in many undergraduate research programs, has significant benefits for students (Kardash, 2000; Seymour et al, 2004).

Most undergraduate research programs follow a four step structure of collaboration that includes (a) identifying and acquiring a disciplinary or interdisciplinary methodology, (b) setting out a concrete investigative problem, (c) carrying out an actual project, and (d) sharing the discovery with peers and the professional community (Dotterer, 2002). Furthermore, Hakim (1998) characterized undergraduate research experiences as resting in four assumptions: (a) that the interaction between the undergraduate research intern and the mentor is focused on student learning, (b) that the research experience will lead to meaningful contributions by the student to the research project, (c) that the procedures and methods used as tools of inquiry by 
the student are consistent with current practices in the discipline, and (d) that the research experience will culminate in a tangible product that is to be critiqued by other members of the discipline.

Two pieces of evidence strongly support the importance of undergraduate research. First, all seven principles for good practice in undergraduate education described by Chickering and Gamson (1999) in their seminal paper apply directly to undergraduate research. Second, several professional organizations have been created to foster undergraduate research, among them, the National Conference on Undergraduate Research and the Council on Undergraduate Research.

\section{Research Questions}

In 2005, Zaras described and summarized the current REU program at the National Weather Center (NWC), but no assessment report was included (Zaras, 2005). The purpose of this paper is to share with the atmospheric science community a partial evaluation of the National Weather Center's REU program in regard to the following questions:

- Is there a statistically significant difference in graduate school plans for 2001-2005 students before and after the summer research experience?

- Is there a statistically significant difference in career plans for 2001-2005 students before and after the summer research experience?

- Is there a statistically significant difference in 2001-2005 students' perceptions of their potential for scientific research before and after the summer research experience?

- In what way do students' written comments reflect the impact of the REU experience?

Most evaluations of undergraduate research programs are for programs in other subject matter areas, including biology, chemistry, geology, physics, and engineering. The few papers that report on undergraduate research programs in the atmospheric sciences tend to cover program goals and activities and post-program education achievement of participants rather than delving much into program evaluation (this paper) or studying the students' experiences in the programs (cited literature and future work). Evaluation of atmospheric science programs may be important, however, because research is not restricted to traditional scientific positions. There are many overlapping career types, such as forecasting in both the public and private sector, where research is often necessary to solve operational problems or give a company a competitive advantage. The study is also innovative in that it combines quantitative and qualitative research components to create a clearer picture of the impact of the REU program on students interested in atmospheric science research. In the social sciences, a mixed method approach to research is commonly used to establish credibility that conclusions drawn from the data are representative of the research subjects' experience(s).

\section{Reviewing effectiveness of undergraduate research programs}

Because there is significant financial, technical, and human investment in undergraduate research programs, their assessment is important (Kardash, 2000; Nnadozie, Ishiyama, and Chon, 2000). Fortunately, there is a significant body of literature supporting the proposition that undergraduate research experiences are an educational and personal-growth experience with many transferable benefits (Bresette and Breton, 2001; Seymour et al, 2004).

One of the benefits for students is that they are capable of producing a research product, usually papers, which are professional in quality (Shellito, 2001). A possible measurement of the quality of the final papers is that they are often accepted for presentation at professional conferences. A subgroup of these is likely to be published in professional journals (Kinkead, 2003; Kremer and Bringle, 1990; Lanza and Smith, 1988). In contrast, research experiences that do not require the preparation of a publishable paper are not as useful in helping students to prepare and be accepted to graduate school (Nnadozie, Ishiyama, and Chon, 2000).

Another benefit is that students perceive that their research skills have improved significantly after the experience compared with peers who did not participate in an REU or REU-like program (Bauer and Bennett, 2003; Gawel and Greengrove, 2005; Kremer and Bringle, 1990). Students report a direct, independent, hands-on engagement in the practice of the science that emphasized learning by doing (Dotterer, 2002; Shellito et al, 2001). They also reported the mastering of complex scientific concepts and the development of advanced critical thinking skills (Ishiyama, 2002). In some cases that research experience can go beyond the summer, where students can work on extensions of their projects (Lanza and Smith, 1988).

Undergraduate research participants tend to use their experience to make important decisions about future goals. Students report that the research experience helped them to clarify, refine, or confirm their pre-existing choice of career direction (Alexander et al, 1996; Seymour et al, 2004). They also report being more confident about their potential success in graduate school (Gentile, 1988; Kremer and Bringle, 1990). Using a carefully designed quantitative methodology and an acceptable sample size, Bauer and Bennett (2003) reported that University of Delaware alumni who had undergraduate research experience were significantly more likely to pursue graduate education and were twice as likely to 
complete doctoral studies compared with alumni with no undergraduate research experience.

Students report that participating in undergraduate research gives a sense of ownership for the results, intrinsic motivation, and a sense of the real struggle scientists face as some experiments do not turn out as expected (Alexander et al, 1996; Kinkead, 2003; Lanza, 1988; Seymour et al, 2004). It is from those mistakes that undergraduate students learn a great deal.

Undergraduate research has also increased the retention and graduation of underrepresented students, usually females and minorities, in certain disciplines, including science (Jonides, 1995; Nagda et al, 1998). Another group that also benefits from undergraduate research programs is poor students. The stipends paid to these students make it practical for them to engage in research full-time during the summer (Gentile, 1988).

As research develops, it is possible for faculty and students to face ethical dilemmas. As a consequence, ethical considerations are explored, discussed, and decisions are made based on careful deliberation. This is a unique opportunity for students to get acquainted with real examples of ethical struggle and learn from it (Kinkead, 2003; Shachter, 2003).

Undergraduate research programs not only have a positive effect on the participating students, but on some of their peers as well. For example, Gentile (1988) reported that other science majors and non-science majors attended symposia lead by REU students to present their research results. Also, he noticed that research participants become leaders in their department and models to other students. This is also the case with some of the NWC REU students, who have presented at their schools and at regional conferences, and become leaders in their local American Meteorological Society (AMS) chapters.

Despite the large number of reports evaluating undergraduate research experiences in positive terms, some specific outcomes are harder to measure. Part of the reason for this is the inappropriateness of standardized assessment methods given the varied backgrounds, preparations, knowledge, and experiences of both mentors and undergraduate researchers (Kardash, 2000). Some limiting factors in assessing the students' real gains produced by the research experience include small size groups and the absence of control group comparisons (Bauer and Bennett, 2003). Also, selfreporting and self-selection are problematic. However, as a whole the literature on undergraduate research experiences is overwhelmingly supportive.

\section{Historical Evaluation of the NWC REU Program}

In 1987, one of the National Weather Center institutions, NOAA's National Severe Storms
Laboratory, established a then-called "summer employment program" for undergraduate students to address two important issues at the time: (a) the scarcity of undergraduate students, especially female and minorities, interested in meteorology in general, and severe storm meteorology in particular and (b) the inability of the educational system to introduce undergraduates to the "business of scientific research" (Lewis and Maddox, 1991). This program was designed to emulate similar programs in existence in the 1960s and 70s at NOAA's Experimental Meteorology Laboratory at Coral Gables, FL, and to complement existing programs such as the National Center for Atmospheric Research's Summer Employment Program at Boulder, CO (Armhols and Woodley, 1975). Since 1991, most summer programs were supported in part by a National Science Foundation REU grant.

The positive impact of the program has been documented from its beginnings through student evaluations. For example, students from the first summer programs at NSSL expressed their unanimous appreciation for the learning and research opportunity provided and their "renewed enthusiasm for science and a better idea of where it fits into their future" (Lewis and Maddox, 1991, p. 1372). Eleven out of seventeen, or about $65 \%$ of the students who did summer research at NSSL were females and/or minorities, an important component at the time.

Around the mid 90s, Cortinas Jr. et al. (1996) summarized the successes of the REU program up to then and summarized the evaluation of the 1995 program. Using a pre-program/post-program questionnaire, students' answers were compared to determine whether the goals of the program were met. It was found that the REU program reinforced most students' decision of attending graduate school and that all students felt better informed about career options in meteorology, with some of them considering a research career seriously. When evaluating the REU program itself, the students' comments were positive, and many were extremely positive. Similar reports of the continuing positive impact of previous REU programs were reported several years later at the American Meteorological Society Symposia on Education (Palmer, 1999; Palmer, Stevenson, and Zaras, 2000).

Evaluation of and reflection on this program have been used to improve it. In its latest form, the NWC REU program uses mentor and student feedback in order to evaluate the program and refine it, while using additional data to begin to explore how these types of programs are effective in helping students make a career choice (Zaras, 2005). Experience as an REU participant in a nuclear physics REU in 1988 and current academic work in adult and higher education enables one of the authors (Zaras) to bring personal reflection informed by research on the college student to this evaluation and 
analysis effort. Gonzales-Espada, with an extensive background in science education, brings program evaluation experience and a fresh, outside perspective for reflection. By sharing our work, we hope to advance the constructive dialogue already begun in and beyond the atmospheric science community with our colleagues running similar programs.

\section{Methodology}

For the quantitative analysis, data collected from REU participants since 2001 was used. Fifty-six percent of the participants were female. About $10 \%$ of the participants who expressed their racial/ethnic background identified themselves as members of a minority group. Almost $91 \%$ of the participants had majors in meteorology or physics, the rest came from mathematics, chemistry, or geography. There is an even split between students who originated from teaching and research institutions but none had equivalent research experience. About $87 \%$ of the participants were junior or seniors. In only one occasion during these years was a first-year student accepted into the REU program.

For the qualitative analysis, only the survey comments from the 2004 participants were used as sources of data. That year, $60 \%$ of the participants were female, $90 \%$ were meteorology majors, and $80 \%$ were juniors or seniors. Students came from both teaching and research universities located in the Illinois, Indiana, Wisconsin, Pennsylvania, Oklahoma and Florida. All data collection occurred in writing, as the participants completed initial, intermediate, and final surveys during the REU program.

To collect data about the students' plans for graduate school, career plans, and their perceived potential to become research scientists, a 5-point Likert scale was designed. In this scale, the extremes were defined as "no", corresponding to the number one, and "yes", corresponding to the number five. The number three, at the middle of the scale, was interpreted as "not sure".

To analyze the first three research questions, we need an appropriate statistical test. Due to the use of Likert scales as a data collection tool, a nonparametric test was used to determine significant differences. According to the literature, the Wilcoxon matched-pairs signed-ranks test, a non-parametric version of a Student's t-test, is the appropriate test for ordinal data (Gibbons, 1993). This test uses as a null hypothesis that the difference between the members of each pair of values has median value of zero. We selected an alpha level of 0.05 to balance the need for a relatively strict significance cutoff point with the reality of a small sample size and the use of a nonparametric test. An alpha level of 0.05 is typically used in social science, psychological, and education research.
For the fourth research question, we used a written survey format to gather information from the participants. Participants were questioned about satisfactions and challenges related to their research projects, potential career plans, attending graduate school, presenting their results, and how much they learned about research in meteorology.

Qualitative data from surveys were combined to create a biographical story of the summer experience of each participant in regard to the four research questions, an appropriate analysis procedure when individual differences may be important (Creswell, 1998). The goal was to explore participants' thinking behind their answers to Likertscale survey questions to see whether there was, in fact, important changes in students' attitudes and perceptions that was not adequately measured by the Likert scale responses. A portion of the qualitative data are included here; all students were included in the longer paper in review with the Journal of Geoscience Education.

We did our best to assure that the survey used demonstrated a satisfactory level of validity and reliability. For example, all available students were used as participants for the quantitative analysis. All students from a specific year were used for the qualitative analysis. This might somewhat overcome self-selection limitations. The survey had clear instructions and straightforward questions to avoid confusion or misinterpretation. The questions, consistent with themes from the REU evaluation literature and specifically designed to fit the research objectives, were written by one of the authors, a person knowledgeable in meteorology, educational research, and the literature on undergraduate research evaluation.

\section{Quantitative Findings}

The question of whether students were planning to attend graduate school was asked at the beginning and at the end of the REU experience. Thirty-eight students answered both questions on the Likert scale provided. At the beginning of the program, the median response on a 1 to 5 scale was 4.25 (mean $=4.46, \sigma=0.63$ ). At the end of the program, the median response was 5 (mean $=4.62, \sigma=0.60)$. In percentage terms, $10.5 \%$ of the participants lowered their final score compared with the initial one. About $36.8 \%$ of the participants increased their score at the end of the REU experience.

The Wilcoxon matched-pairs signed-ranks test detected a significant difference between the students' paired responses $\left(\mathrm{W}_{+}=35, \mathrm{~W}-=136, \mathrm{p}<\right.$ $0.05)$. Based on this test, we concluded that students came to the REU program with a good idea that they wanted to continue graduate school and left more committed to attend graduate school.

The question of whether participants had well-defined career plans was asked at the beginning 
and at the end of the REU experience. Thirty-eight students answered both questions on the Likert scale provided. At the beginning of the program, the median response was 3 (mean $=3.02, \sigma=0.75$ ). At the end of the program, the median response was still 3 (mean $=2.97, \sigma=1.12$ ). In percentage terms, $28.9 \%$ of the participants lowered their final score compared with the initial one. About $31.6 \%$ of the participants increased their score at the end of the REU experience.

The Wilcoxon matched-pairs signed-ranks test did not detect a significant difference between the students' paired responses $(\mathrm{W}+=131.5, \mathrm{~W}-=144.5$, $p>0.05)$. Based on this test, we concluded that students might come into the REU program without a well-defined picture of their career plans and left the program without improving their career goals.

Students were also asked at the beginning and end of the REU experience whether they saw themselves becoming research scientists. Thirty-six students answered both questions on the Likert scale provided. At the beginning of the program, the median response was 4 (mean $=3.83, \sigma=0.64$ ). At the end of the program, the median response did not change (mean $=3.67, \sigma=0.85$ ). In percentage terms, $27.8 \%$ of the participants lowered their final score compared with the initial one. About $16.7 \%$ of the participants increased their score at the end of the REU experience.

The Wilcoxon matched-pairs signed-ranks test did not detect a significant difference between the students' paired responses $\left(W_{+}=94, W_{-}=42, p>\right.$ $0.05)$. Based on this test, we concluded that students completed the REU program but the experience did not significantly change their self-efficacy on becoming research scientists, which was relatively high to start with.

\section{Qualitative Findings}

In this section, survey comments from the 2004 REU participants are presented. This data comes from an initial survey, intermediate survey, and end-of-program survey, and a post-professional conference presentation survey. The questions were designed for the students to elaborate on their Likert scale scores to the questions about the students' plans for graduate school, career plans, and their perception of becoming a research scientist. In order to see what the effect of the REU experience is on individual participants, each person's statements are presented in biographical format. The reported names of the participants are pseudonyms to assure the confidentiality of their responses. The full paper includes all students and a minimal aspect of triangulation on student self-efficacy by including information from mentor surveys.

\section{Darren}

Darren started the summer sure he would attend graduate school but not sure he would like research:

"My main thought on grad school is that it is necessary if I want to do research (which I haven't really decided whether or not I want to do yet) and I see it as being beneficial in any other job I take (forecasting, private sector, etc.)..." He did see himself as a potential scientist, however, saying "I think [research] would be really interesting and something that I would find rewarding and that I would not get bored with." He thought research would be a mix of "exciting and fun" and "dull and boring" but that getting good results would make "the fun parts that much better and the less exciting parts that much more worthwhile in the end."

The students had an opportunity to hear talks by the National Council of Industrial Meteorologists when the NCIM held their annual meeting in Norman. This student mentioned that the talk gave him new information on potential career paths:

"I enjoyed this talk quite a lot. [I have] been interested in looking into the private sector of meteorology for quite some time, but never really knew what was out there/what sort of jobs were available."

Also on the intermediate survey he said his project was going "quite well" even though much of what he'd done thus far was not necessary for his actual paper. His data was going to be used in later work, some of his time having been spent getting his data set up for analysis. He found his own analysis of the data interesting and said:

"Actually seeing what it has to say has been really rewarding and has even inspired new ideas that I think would be interesting to look at that weren't even part of the foci set out for my project. All in all, I am finding the research I'm doing to be very enjoyable and rewarding."

At the end of the summer Darren said he enjoyed his research project: "just to think that I was working on cutting edge developments as far as models are concerned... I learned a great deal." He said, "I found I would get excited about it just talking to some of the other REU students trying to explain to them what I was doing..."

Darren expressed his hopes in becoming a researcher, but also enjoyed interacting with the forecasters at the Storm Prediction Center. He said: "I think it is entirely possible that I could end up doing any combination of these things (research for a few years, then forecasting and then maybe consulting or something to that effect)... I think that at this point my goal is to set myself up to keep as many options open as possible when it comes to choosing a career." 
This student found presenting his work in a poster at AMS a nice way to close out the whole research experience. He met a lot of new people who were interested in his work, even talking to a student from another school for half an hour: "Where else is something like that going to happen except at a conference?!"

The student conference in particular was helpful in making "the future seem a bit less daunting" while opening up possibilities he hadn't considered before. He felt he had a better idea "of what's out there and what's to come." Meeting faculty from particular schools was very helpful, and resulted in him ranking prospective schools differently. He was able to add a graduate school program to his list after becoming interested in transportation and finding a school he didn't apply to had research ongoing in that area.

\section{Frances}

Frances rated her career goals much higher at the end of the summer than the beginning, even though she was still very unclear what she wanted to do within meteorology. It appeared she was not completely certain that meteorology was for her. This particular student was younger than most and might not have spent as much time considering careers.

On her initial survey she was not certain about graduate school, using the contingency, "if I go to grad school." When asked what she thought research scientists were like, she used words that tended to be negative, yet she felt she could see herself as a scientist because "I am a nerd and that is the best place for me to be."

She was mostly positive about her experiences on the intermediate survey, despite frustrations with the length of time it took to process her data. "I am enjoying the research; however there are times in which I feel like I need to take a break because staring at a computer screen and waiting for it to finish processing takes forever!" In the question/answer period we added to the third practice talk, she realized how shallow her understanding of her project was:

"I realized that I needed to really think hard about my subject and learn a few things about it. After I got a talk from [my mentor] on Friday, I learned a lot more about my topic. My wonderful way of thinking has made me get misconceptions on my subject..."

On the final survey she said, "I will admit in the middle I hated it" and "anyone else's project was better than mines." Despite keeping a journal and reflecting daily on her experiences, her overall outcome was typical of previous years, showing attraction to two very different career paths: "I would not mind being in research or forecasting or both." When asked if she could see herself as a scientist, she said:
"I can definitely see myself as a research scientist. I really liked my experience at [an institution in the NWC]. This summer has just opened so many options for me that I really can not see where I am going to be in a few years down the road... this summer taught me that I can cut it being a research scientist"

\section{Gerard}

Gerard is strongly oriented to careers with social components, so while this student is more certain about graduate school, it is a result of knowing it will help him achieve a non-research career. In his comments, he mixes both a concern about the social aspects of the career with a personal value of wishing to work for the common good that may have been his attraction to research. When asked about employment prospects he mentioned he may wish to teach and that science teachers are in demand. When asked how his project was going on the intermediate survey he said:

"It is going well. I do not know that I am enjoying it. It is interesting, but all the stats and computer work is not how I picture my future."

On the final survey Gerard said of his mentors, "they mentored me very well to give me perspective when writing and seeing the big picture of my research." In the end he said: "I enjoyed my research project. I enjoyed using my mind at work. But I could have thought of more interesting research that I could have been a part of."

He was disappointed not to have more career focus as the program ended, saying, "it really just opened my mind to many more options, and I really feel overwhelmed and confused right now." He was tending away from research because "I want to touch a variety of people's lives on a daily basis."

\section{Irene}

Irene appears to have less self-efficacy than others, saying "I don't know if I can live up to being a research scientist or not, yet." She was leaning toward going to graduate school and hoped to get involved in research. She was concerned about financial issues and needed to "know that research is [her] path." She feared the process of research would be "a lot of hard, tedious work."

On the final survey she said her research project was great, pointing out the tentative nature of research as she says:

"The unexpected would happen once in awhile and this would keep me on my toes. I also had to use my brain... During this REU I had to make some of my own decisions, and this was quite thrilling."

She said, "I believe that everyone has a purpose and I would like to make sure I'm not blowing off my true purpose by quickly jumping in to something just because it was fun for the summer." 
Her most memorable experience was when she "got frustrated because I wasn't finding what I was looking for. It turned out that not finding what I was looking for was a huge finding." She said, "I guess I liked this for two reasons. 1. The unexpected outcome turned out to be one of the most important parts of my project. 2 . The people who are experts on this sometimes get confused or are surprised by the unexpected. This made me feel less out of place."

\section{Discussion}

The only statistically significant difference before and after the REU experience was detected in their plans toward graduate school. The undergraduate experience seemed to reinforce an already high desire to continue graduate studies, especially because they recognize that most of the mentors and forecasters have graduate degrees.

The non-significant results related to welldefined career plan are interesting. A look at the qualitative data provides possible explanations for this. Several students mentioned being overwhelmed by the number of possible career options within meteorology they discovered through the summer. We did not see the students frustrated or unhappy about their careers. They were excited about recentlydiscovered opportunities that were highly compatible with their interests. We called this "happy confusion." Rogers (2003) talked about a similar aspect to the diffusion of innovations, namely that complexity in a new idea tends to delay adoption or acceptance of that idea.

The other non-significant quantitative result was related to their perceptions of becoming scientists. Because most of the students did not have research experience, the REU program might have served as a way to show students how research is really done. This might have shattered some of the students' idealized vision of scientific research, which might discourage them from considering research as a career option. Conversely, those realities might have "hooked" those students who were not sure what to think about research. It is possible that these effects might cancel out, showing as non-significant results when the group is taken as a whole.

A quick look at the qualitative data suggests that this is the case. Students mentioned positive aspects of their research experience, such as the opportunity for some students to choose their projects, the amount of declarative and procedural knowledge learned, the independence of thought developed, the skill in expecting the unexpected from research, and the feeling of accomplishment when an important result is found. Students also lived the negative, but all too real, aspects of scientific research, such as the social isolation as hours are expended working with a computer, the monotony of large-scale data entry, the feeling that there are so many variables and parameters in continuous interaction there is no way to control for all foreign variables, the lack of focus as their attention shifts from one sub-problem to the next or one sub-routine to the next, and the lack of self-motivation when the mentor gives the student too much independence.

Overall, the REU program attempts to provide the most realistic research experience possible. Although one of the goals of a program like this is to attract qualified students into research, if the students' experiences help them clarify their goals with respect to being a researcher either way, the program has met an important objective.

Some interesting themes can be identified from the qualitative data. For example, several students mentioned the fact that they felt that their effort, knowledge, and research were valued by their peers. We all know that sometimes science is not the most popular subject in college. This might lead to feelings of social isolation. This is not the case during the summer program. The students have a lot in common. They attend seminars, workshops, and field trips. They were chosen to work in one of the best known centers of severe storm research. They worked on cutting edge research projects with motivated mentors and an effective support system. It is possible these factors contribute to enhanced selfconfidence.

Based on the student's comments, a few general recommendations for similar undergraduate research programs are inferred and included in the full paper.

\section{Conclusion}

There is overwhelming evidence that undergraduate research programs are having a positive impact on students' decisions to pursue careers in science. An analysis of the evidence from the NWC REU program supports this assertion. Since the late 1980s the National Weather Center has contributed to this area by providing students an opportunity to do research, attend seminars, and visit the NWC facilities in Norman, Okla. Evaluation data provided by the students suggests that they leave the program with a more certain idea about attending graduate school.

It was also found that the research experience is providing students a wealth of information about career options that are apparently overwhelming for most students. There is no doubt that career clarification towards meteorology careers is going on, which is a positive impact of the program. In addition, the fact that the research experience is as real as possible shows students both the positive and not so positive aspects of scientific research. The data supports the notion that some students become more interested in science after their experience, while others might realize research was not what they thought. Although the quantitative data seems to 
suggest that the REU program has no effect on career choice or whether students see themselves as scientists, the qualitative data provides a rich context that strongly supports the notion that the NWC REU program is having a positive impact on students. As always, research findings should be examined carefully for limitations. In our case, several limitations are apparent. First, our participants are not selected randomly, so self-selection might create a biasing problem. Second, it is possible that some students might have not been honest in their evaluation, providing positive responses to please the REU program director. Third, the use of survey questionnaire instead of interviews prevented the researchers from asking follow up or clarification questions that would have provided individual context for the students' experiences throughout the summer. Fourth, due to limited sample size, non-parametric tests were used, although it is well known they might not be as powerful as parametric ones. Fifth, despite efforts to understand qualitative analysis, most of our experience deals with quantitative data analysis, so it is possible that qualitative data could be presented, interpreted, and explained from a different perspective. Overall, we think that the data were clear enough to suggest a positive impact of the program, which is consistent with evaluations from other undergraduate research programs.

\section{Acknowledgments}

This material is based upon work supported by National Science Foundation Grant No. 0097651, under the direction of Ms. Daphne S. Zaras, NWC REU, 100 E. Boyd, Suite 1110, Norman, OK 73019 (www.caps.ou.edu/reu). Its content is solely the responsibility of the authors and do not necessarily represent the official views of NSF. Ms. Zaras' affiliation with CIMMS was facilitated through the NOAA Office of Oceanic and Atmospheric Research under NOAA-University of Oklahoma Cooperative Agreement \#NA17RJ1227, U.S. Department of Commerce at the time of the work in this report.

\section{References}

Alexander, B. B., Lyons, L., Pasch, J. E., and Patterson, J. (1996). Team approach in the first research experience for undergraduates in Botany/Zoology 152: An evaluation report. Madison, WI: The LEAD Center. ED 412096.

Armhols, C. A. and Woodley, W. L. (1975). Teaching and learning with youth. Bulletin of the American Meteorological Society, 56(1), 41-44.

Bauer, K. W. and Bennett, J. S. (2003). Alumni perceptions used to assess undergraduate research experiences. Journal of Higher Education, 74(2), 210-230.

Bressette, A. R. and Breton, G. W. (2001). Using writing to enhance the undergraduate research experience. Journal of Chemical Education, 78(12), 1626-1627.

Chickering, A. W. and Gamson, Z. F. (1999). Development and adaptation of the seven principles of good practice in undergraduate education. New Directions in Teaching and Learning, 80, 75-81.

Cortinas, J. V., Straka, J. M., Beasley, W. H., Schneider, J. M., and Machacek, C. M. (1996). The Research Experience for Undergraduates Program: The 1995 program at the Oklahoma Weather Center. Bulletin of the American Meteorological Society, 77(12), 2925-2936.

Creswell, J. W. (1998). Qualitative inquiry and research design: Choosing among five traditions. Thousand Oaks, CA. Sage Publications.

Dotterer, R. L. (1992). Student-faculty collaborations, undergraduate research, and collaboration as an administrative model. New Directions in Teaching and Learning, 90, 81-89.

Gawel, J. E., and Greengrove, C. L. (2005). Designing undergraduate research experiences for nontraditional student learning at sea. Journal of Geoscience Education, 53(1), 31-36.

Gentile, J. M. (1988). The NSF-REU program at Hope College: Education through research. Journal of College Science Teaching, 18(2), 116-117.

Gibbons, J. D. (1993). Nonparametric statistics: An introduction. Newbury Park: Sage Publications

Hakim, T. (1998). Soft assessment of undergraduate research: Reactions and student perspectives. Council on Undergraduate Research Quarterly, 18(4), 189-192.

Halstead, J. A. (1997). Council on Undergraduate Research: A resource (and a community) for science educators. Journal of Chemical Education, 74(2), 148-49.

Ishiyama, J. (2002). Participation in undergraduate research and the development of political science students. Paper presented at the Annual Meeting of the American Political Science Association, Boston, MA, 28 August.

Jonides, J. (1995). Evaluation and dissemination of an undergraduate program to improve retention of at-risk students. Ann Arbor, MI: Michigan University. ED 414841.

Kardash, C. M. (2000). Evaluation of an undergraduate research experience: Perceptions of undergraduate interns and their faculty mentors. Journal of Educational Psychology, 92(1), 191-201.

Kinkead, J. (2003). Learning through inquiry: An overview of undergraduate research. New Directions for Teaching and Learning, 93, 5-17.

Kremer, J. F. and Bringle, R. G. (1990). The effects of an intensive research experience on the careers of talented undergraduates. Journal of 
Research and Development in Education, 24(1), 1-5.

Lanza, J. (1988). Whys and hows of undergraduate research. BioScience, 38(2), 110-112.

Lanza, J. and Smith, G. C. (1988). Undergraduate research: A little experience goes a long way. Journal of College Science Teaching, 18(2), 118-120.

Lewis, J. M. and Maddox, R. A. (1991). The summer employment program at NOAA's National Severe Storms Laboratory: An experiment in the scientific mentorship of undergraduates. Bulletin of the American Meteorological Society, 72(9), 1362-72.

Mortenson, P. K. (1988). Research experiences for undergraduates: An investment in our future. Journal of College Science Teaching, 17(3), 210-211.

Nagda, B. A., Gregerman, S. R., Jonides, J., von Hippel, W., and Lerner, J. S. (1998). Undergraduate student-faculty research partnerships affect student retention. The Review of Higher Education, 22(1), 55-72.

Nnadozie, E., Ishiyama, J., and Chon, J. (2000). Undergraduate research internships and graduate school success. Paper presented at the annual meeting of the Missouri-KansasNebraska Chapter of the Mid-America Association of Educational Opportunity Program Personnel, Kansas City, MO, 12-14 April.

Palmer, M. H., Stevenson, S., and Zaras, D. S. (2000). Student evaluations of the Oklahoma Weather Center REU Program 1995, 1998, and 1999. Paper presented at the $9^{\text {th }}$ Symposium on Education, American Meteorological Society, Long Beach, CA, January 9.

Palmer, M. H. (1999). Research experience for undergraduates at the Oklahoma Weather Center: Summer 1998. Paper presented at the $8^{\text {th }}$ Symposium on Education, American Meteorological Society, Dallas, TX, January 10.

Rogers, E. M. (2003). Diffusion of innovations. 5th ed. New York: Free Press.

Shachter, A. M. (2003). Integrating Ethics in Science into a summer undergraduate research experience. Journal of Chemical Education, 80(5), 507-512.

Seymour, E., Hunter, A.B., Laursen, S. L., and Deantoni, T. (2004). Establishing the benefits of research experiences for undergraduates in the sciences: First findings from a three-year study. Science Education, 88(4), 493-534.

Shellito, C., Shea, K., Weissmann, G., Mueller-Solger, A, and Davis, W. (2001). Successful mentoring of undergraduate researchers. Journal of College Science Teaching, 30(7), 460-464.
Zaras, D. S. (2005). Activities, findings, and recent developments of the National Weather Center Research Experience for Undergraduates Program. Paper presented at the $14^{\text {th }}$ Symposium on Education, American Meteorological Society, San Diego, CA, January 11. 